\title{
2q23.1 microdeletion syndrome
}

INSERM

\section{Source}

INSERM. (1999). Orphanet: an online rare disease and orphan drug data base. 2q23.1 microdeletion syndrome. ORPHA:228402

The newly described 2q23.1 microdeletion syndrome includes severe intellectual deficit with pronounced speech delay, behavioral abnormalities including hyperactivity and inappropriate laughter, short stature and seizures. 